\title{
Govier on Trust
}

\section{Robert C. Pinto}

Centre for Research in Reasoning, Argumentation \& Rhetoric

University of Windsor

Windsor, $O N$

Canada N9B 3P4

pinto.robert@gmail.com

\begin{abstract}
This paper attempts two things: (a) to give the reader a very general idea of the main outlines of what Govier has to say both about social and political trust and about trust in personal relationships, and (b) to present in slightly more detail what she says about the role of trust in acquiring belief and/or knowledge from testimony and about the reasons for trusting such testimony.
\end{abstract}

\begin{abstract}
Dans cet article je vise à: (a) donner au lecteur une idée très générale des grandes lignes de ce que Govier a à dire sur la confiance sociale et politique et sur la confiance dans les relations personnelles, et (b) présenter en un peu plus de détail sur ce qu'elle dit à propos du rôle de la confiance dans l'acquisition des croyances et/ou des connaissances à partir des témoignages et sur les raisons de faire confiance à un tel témoignage.
\end{abstract}

Keywords: Jonathan Adler, H.H. Price, Fred Kauffeld, implicit trust, innocent trust, interpersonal trust, reasons for trusting, reflective trust, social trust, testimony

\section{Introduction}

In a series of recent papers (Pinto 2006, 2009, 2011a) I've been strongly influenced by Rescher's remark (1988, p. 4) that

[r]ationality... pivots on the deployment of 'good reasons': I am being rational if my doings are governed by suitably good reasons - if I proceed in cognitive, practical and evaluative contexts on the basis of cogent reasons for what I do.

(C) Robert C. Pinto. Informal Logic, Vol. 33, No. 2 (2013), pp. 263-291. 


\section{Robert C. Pinto}

That remark suggests that understanding rationality requires understanding the interplay among cognitive, conative (or practical) and evaluative attitudes. In the attempt to investigate more closely the role that evaluative attitudes play in our lives as rational agents, I recently investigated the interplay between emotions and reasons in Pinto 2011 b, and concluded that emotions contain as "ingredients" both evaluative attitudes and cognitive attitudes such as beliefs. Since then I have examined what Trudy Govier has written about hope (Govier 2011), which I take to be an evaluative attitude, and about trust-which like emotion appears to contain both cognitive attitudes such as expectations and as well evaluative attitudes (or "feelings") toward individuals who are trusted.

One of Govier's books on trust has been reviewed in Informal Logic (see Friend 2000). However, it strikes me that her work on trust has received less attention in the argumentation community than it deserves and that this issue of Informal Logic would be an appropriate occasion to call the attention of that community to it.

Govier has addressed trust in an extended series of papers and books, most of which date from the early to the late 1990s. Given the extent and richness of those publications, this paper will attempt only two things: (a) to give the reader a very general idea of the main outlines of what Govier has to say both about social and political trust and about trust in personal relationships, and (b) to present in slightly more detail what she says about the role of trust in acquiring belief and/or knowledge from testimony and about the reasons for trusting such testimony.

\subsection{The scope and thrust of Govier's work on trust}

Govier has at least eight or nine papers dealing with a variety of specific topics having to do with trust (see the titles of Govier's papers listed in the references below, which in most cases make it clear what their topic is), as well as two books dealing with the topic.

Each of the two books opens with a chapter describing what trust, in general, is and then for the most part discusses trust in one

(C) Robert C. Pinto. Informal Logic, Vol. 33, No. 2 (2013), pp. 263-291. 
or another context or area of human activity, or in relation to one or another problem. Thus Chapters 2 through 9 of Govier 1997 (Social Trust and Human Communities-hereafter referred to as Social Trust) deal respectively with trust in connection with the construction of social reality, with testimony, with the professions, with strangers, with lower-trust societies, with totalitarianism and civil society, with politics and leadership, and with trust and distrust between groups. Chapter 2 through 6 of Govier 1998 (hereafter referred to simply as Dilemmas of Trust) deal with trust in connection with friendship, with the family ( 2 chapters), and with selftrust, self-respect and self-esteem (2 chapters); while chapters 8 through 10 deal with distrust, with restoring trust, and with forgiveness and reconciliation.

Chapter 7 of Dilemmas of Trust, which I consider a central chapter of that book, is entitled "Reasons for Trust and Distrust"; it lists (p. 121) six "factors" that we may consider when "reflecting on the reasons that a person...may have for trusting or distrusting another individual." The six factors are: information, actions and statements, "exceptions" clauses, character, circumstances, and judgment. The bulk of the chapter consists of sections on each of the "factors" in which Govier tries to make clear how consideration of that factor can help us determine whether a person's reasons for trusting or distrusting someone to one or another degree are good reasons.

Though the presentational style or Govier's work on trust is usually not especially technical, she interacts extensively with the literature on trust that existed by the 1990s: (a) with philosophical writing dealing explicitly with trust (for example, Annette Baier, H.H. Price, C.A.J. Coady, Alex Michalos, Jonathan Adler), (b) with the broader philosophical literature that has at least an indirect bearing on aspects of the topic, (c) with feminist literature (especially in Govier 1992b, 1993b, and 1993d), and (d) with relevant work by psychologists, sociologists and political scientists. Even though the literature devoted explicitly to trust has been limited, working through Govier's accounts of many aspects of it- 
especially in Social Trust and Dilemmas of Trust-introduces the reader to a surprisingly wide-ranging conversation. By drawing on views with which she agrees (such as Coady's and to some extent Baier's) and by offering sympathetic accounts of a series of views she does not endorse-while presenting balanced andsound criticisms of those other views - she enables her reader to achieve a deeper and more nuanced understanding of the phenomenon of trust.

\section{Central ideas in Govier's treatment of trust}

\subsection{What is trust?}

Govier's account of what trust is can found in the opening pages of her two books on the subject (Social Trust, pp. 4-7 and Dilemmas of Trust, pp. 6-9), as well as in passages in some of her papers (for example Govier 1992b, p. 17 or 1994, pp.238-39). In my estimation, there are four key points in her account of what trust is.

(1) "Trust is fundamentally an attitude based on beliefs and feelings, and implying expectations and dispositions" (Social Trust, p. 4; see also Dilemmas of Trust, p. 6).

(2) "Trust it typically founded on a sense of the sort of person the other is, with regard to motivations and to competence" (Social Trust, p.4): "When we trust, our positive expectations have two basic dimensions: motivation (the other intends to act well and does not intend to do harm) and competence"; see also Dilemmas of Trust, pp. 6-7.

(3) "Trust is not an all or nothing thing. We may trust to varying degrees (we may trust some people more than others). Furthermore, trust and distrust are often relativized to specific roles or contexts" (Social Trust, p. 5). See also Dilemmas of Trust, p. 121: "Both trust and distrust are susceptible to degrees; we may trust or distrust another slightly, moderately or completely. Both attitudes are often relative to context:

(C) Robert C. Pinto. Informal Logic, Vol. 33, No. 2 (2013), pp. 263-291. 
we might, without hesitation, trust a person to deliver a parcel and yet feel ambivalent about trusting him to repair a computer."

(4) "Trust presupposes beliefs, and often these beliefs are based on evidence.... There are good reasons for deeming people trustworthy or untrustworthy, and there seems to be considerable agreement on these" (Social Trust, p. 5; see also Dilemmas of Trust, p. 7). ${ }^{1}$

\subsection{Distinction between social trust and interpersonal trust}

Govier 1994 (pp. 238-39) calls attention to the difference between (a) the trust that exists between intimates, lovers, friends and colleagues and (b) the trusting attitude we can have "towards people with whom one has only a slight personal relationship —or even none at all." The latter sort of trust occurs both in relationships based on social role (doctor, dentist, lawyer, teacher, accountant, and so on) and in relationships with strangers with whom we interact (meat packers, car mechanics, maintenance personnel and drivers on the road).

In Chapter 2 of Social Trust (a chapter which covers most of the territory covered in Govier 1994), the distinction between (a) and (b) is introduced as a distinction between social trust and interpersonal trust. She writes (p. 31):

Social trust and interpersonal trust are different in significant ways. Interpersonal trust is based on experience, sometimes deep and intimate experience, with another individual. In some cases of social trust we may have limited experience with the other persons involved, in others we have none at all.

\footnotetext{
${ }^{1}$ It is worth noting that Govier (Social Trust, p. 8) says, "The attitude of trust presupposes inductively grounded beliefs and confident expectations that go further than strict induction would warrant."

(C) Robert C. Pinto. Informal Logic, Vol. 33, No. 2 (2013), pp. 263-291.
} 
But despite these differences, she writes (1994, p. 239; see also Social Trust, pp. 6-7 for a similar point):

Trust based primarily on social role is different in emotional tone from trust between family members, lovers or close friends. Its logic and structure, however, are essentially similar: here too trust entails positive expectations about what the other is likely to do, based on a sense of her competence and motivation, a willingness to allow oneself to be vulnerable and a disposition to interpret what the other person says and does in a positive way.

In addition to social trust and interpersonal trust, Govier also recognizes self-trust as an important category of trust-it is discussed at length in Govier 1993b and in Chapters 5 and 6 of Dilemmas of Trust.

In the preface to Dilemmas of Trust (p. vii) Govier explains the difference between the subject matter of her two books on trust by saying that her "reflections on social and political trust may be found in Social Trust; those on self-trust and trust in personal relationships constitute the present work [i.e., Dilemmas of Trust]".

\subsection{The role of trust in human affairs generally}

A recurring theme, especially in Govier Social Trust and Dilemmas of Trust, is that in most societies trust is virtually ubiquitous, and that it is essential to social functioning. She introduces that theme early in Dilemmas of Trust, observing first (p. 5) that

[w]e tend to take trust for granted: when people whom we trust do as we expect, we barely notice the fact. To understand the nature and importance of trust, we have to make explicit what is characteristically implicit.

She goes on to point out (p. 6) that

[i]n so many ways, we depend on other people and are vulnerable to them. In so many ways, they do not let us down.

(C) Robert C. Pinto. Informal Logic, Vol. 33, No. 2 (2013), pp. 263-291. 
In complex modern societies, nearly everyone nearly every day implicitly places his or her trust in dozens - even hundreds - of other people when speaking, listening, reading, shopping, banking, driving, cooking and performing numerous other mundane activities. Trust, sociologists have said, is the "glue of society."

Indeed, she says (Dilemmas of Trust, p. 205), "Without trust, personal and social life would be impossible."

And like others such as Price (1969, Lecture V), Coady 1992 and even Adler 2012, she emphasizes the enormous extent to which what we believe and know depends on what others have told us and therefore depends on our trusting them and what they say.

At the same time, Govier is quick to point out (Dilemmas of Trust, p. 8) that

[t]rust is a risky business because the people whom we trust can let us down, and we are vulnerable to harm when they do so. It is important to attend to the risks of trust and not to take the simplistic view that trust is always good. Sometimes we trust too easily and risk a great deal in doing so.

\subsection{Innocent, implicit and reflective trust}

In Chapter 3 of Govier Social Trust, which is primarily concerned with trust and testimony, Govier introduces important distinctions between three kinds or levels of trust. As I see it, the value of these distinctions isn't limited to issues surrounding testimony, so I will introduce them here.

(a) Innocent trust. Govier writes (Social Trust, p. 66)

At the earliest stages of learning we have what might be called an innocent trust in those who are guiding us. At this stage, the question of their being mistaken, misguided or malicious does not arise. We simply follow along, assuming

(C) Robert C. Pinto. Informal Logic, Vol. 33, No. 2 (2013), pp. 263-291. 
so thoroughly that everything is all right that we never consider doubts; we could not even articulate doubt.

She observes that such simple acceptance "is, in effect, what Wittgenstein describes in On Certainty, where he emphasizes repeatedly how doubt, belief and knowledge all presume a foundation of taking things for granted."

(b) Implicit trust. Govier writes (p. 67) that at later stages of life

our trust is no longer the innocent trust of the child. Trust and acceptance constitute a kind of default system, operative unless there is reason to pause and reflect.

She mentions two sorts of reason to pause and reflect regarding testimony-(i) suspecting inaccuracy (for example, what somewhat tells us conflicts with what we currently believe or think we know) and (ii) suspecting insincerity (for example, where the other person has a vested interest in our coming to believe what he or she says, or seems pushy, dishonest, manipulative, etc.).

(c) Reflective trust. Govier writes (still on p. 67),

If, after pause and reflection, we nevertheless come to accept a claim made by another, our acceptance is still based on a kind of trust. We still acquire the belief from another person, and we remain to some extent dependent on what he says. But our trust in such a case is reflective, qualified and carefully considered.

I will return to the subject of reflective trust in Section 3 below. But it should be clear that reflective trust requires us to have a rational basis on which to judge this or that individual as trustworthy-as someone it is reasonable for us to depend on whether it be as a source of information or as someone on whom we might rely for a wide variety of different purposes.

\subsection{An example}

(C) Robert C. Pinto. Informal Logic, Vol. 33, No. 2 (2013), pp. 263-291. 
To convey the flavor of how Govier interacts with the existing literature on trust, let me sketch the final section ("High Trust and Low Trust") of Social Trust, Chapter 5 ("Trusting Stran-gers?"). There Govier describes (p. 127 ff.) the work of social psychologist Julian Rotter, who in 1967 had published "an Interpersonal Trust Scale (ITS) [that] was intended to measure 'a general expectancy held by an individual that the word, promise or written statement of another individual or group can be relied upon'." Govier reports that he "used the scale to distinguish between high-trusting and low-trusting subjects." According to Govier (p. 129):

The ITS scale was designed to deal only with generalized expectancies. It was relevant to the issue of trusting an individual stranger about whom we know absolutely nothing....

So far as the unknown individual is concerned, "high trusters" have a normal or default attitude of slight trust and "low trusters" one of slight or moderate distrust.

Interesting findings reported in 1980 included the following (pp.129-30):

Rotter found that high trusters were more trustworthy than low trusters.... He also found that "everyone likes a high truster." People viewed high trusters as happier, more ethical, more attractive to the opposite sex, more desirable as close friends, and more likely to have had a happy childhood than low trusters. Having a tendency to trust did not indicate gullibility. On the contrary, there was some indication that high trusters were less gullible than low trusters because they were more sensitive to cues.

Govier observes (p. 131):

Rotter's conclusion that high trust people tend to fare better in life than low trust people is plausible and could be used as 


\section{Robert C. Pinto}

the basis for an argument that we should try to trust people more than we do, as was claimed by Alex Michalos. ${ }^{2}$

Govier then goes on (pp. 131-32) to report the views of political scientist Francis Fukuyama "who argues for the benefits of trust." Fukuyama distinguishes between "high trust societies" and "low trust societies" and argues (p. 132) that "only in high trust societies are people able to form, manage and preserve large corporations."

But do Rotter's evidence and Fukuyama's arguments provide reasons for claiming that slight trust ought to be our default attitude toward others? Even though in Chapter 3 of Social Trust she had maintained that our default attitude toward anyone offering testimony ought to be trust, she is not convinced by Rotter's evidence and Fukuyama's arguments that "slight trust" should be our default attitude toward strangers "across the board," as it were. She closes Chapter 5 with the following remarks (p.134), which I think are worth quoting in full:

What these arguments do not recall is our vulnerability when we trust. Both Rotter and Fukuyama seem willfully insensitive to the existence of cases in which distrust is warranted or people are greatly harmed because they have trusted. In some contexts we risk life itself. Having a high-trust attitude to other people may be generally beneficial, but there are some contexts, and indeed whole societies, in which trusting strangers is too risky to be sensible. What people expect of others depends on their culture, religion and material and political circumstances. If relatives simply disappear, if one is starved, beaten, and tortured, if friends and colleagues may be spies for a brutal regime, people are unlikely to be high trusters and a recommendation to trust more makes little sense. Although there are no societies without trust and none without interdependence, the webs and patterns of trust

\footnotetext{
${ }^{2}$ Michalos' view on this score, and his arguments for it, were described at length and critiqued in Govier 1994 and in Chapter 2 of Social Trust.

(C) Robert C. Pinto. Informal Logic, Vol. 33, No. 2 (2013), pp. 263-291.
} 
and the sorts of trust that are productive and sensible vary enormously from one type of society to another. ${ }^{3}$

\section{Trust and testimony}

\subsection{Trust and testimony: The problem}

In the first paragraph of Chapter 3 of Social Trust ("Needing Each Other for Knowledge") Govier observes:

One of the clearest and most important areas in which social trust exists is that of knowledge and belief. If we did not trust the word of other people, we would not have beliefs beyond our own immediate experience. In fact, we would not have a language. Knowledge based on what other people tell us presupposes trusting other people. Accepting evidence from others is reasonable only to the extent that we regard them as reliable, competent and sincere. And this is to say that it is reasonable only to the extent that we trust them.

In the first section of that chapter ("Depending on what others tells us"), she follows Coady (1992) in insisting on the necessity (p. 52) and "central importance" (p. 53) of the testimony on which we depend, drawing on examples taken from from John Hardwig (1988) and Steven Shapin (1994).

At the heart of this chapter, however, is the problem of " $j u s$ tifying our reliance on testimony." " In Govier 1993a (p. 16) she

\footnotetext{
${ }^{3}$ In Dilemmas of Trust (Chapter 7, p. 136), she notes that "[s]ome people would say that, in the absence of any specific grounds or reasons to distrust, slight trust is clearly the attitude to be adopted." That sentence references note 16 to the chapter, in which Govier refers the reader to the discussion of this view in Social Trust, and references Rotter 1980 and Logstrup 1997.

${ }^{4}$ I am quoting the title of the section that begins on Social Trust, p. 62, with emphasis added. I should also add that Govier has already made it clear (pp. 56-57) that her interest in testimony is not limited, as it is for example in legal contexts,
}

(C) Robert C. Pinto. Informal Logic, Vol. 33, No. 2 (2013), pp. 263-291. 


\section{Robert C. Pinto}

had cited Anscombe's (1979) view that "believing people is as basic as and not reducible to believing propositions" and that "believing someone is trusting him for the truth"- - view that she emphasizes again in Social Trust (p. 58), saying there that "believing persons is more fundamental than believing propositions."

Govier formulates the central problem $(1997$, p. 62) in the following words: "How can we justify our extensive reliance on other people for knowledge?" This way of formulating the problem appears, on the surface at any rate, to differ from what Adler 2012 calls "the vulnerability problem"-a problem which is central to his account of the epistemology of testimony and which he formulates as the problem of whether a hearer has good reason to ascribe authority to a speaker. ${ }^{5}$

Govier maintains (Social Trust, p. 62) that there are "two levels of questions about justification."

(a) "First, there is the general question of what justifies us in any reliance on the other people's testimony. What, if anything, makes it appropriate ever simply to accept what other people tell us is true, as a basis for our knowledge or reliable beliefs?"

to eyewitness testimony and expert testimony. Though the distinctions between these various forms of testimony are interesting, "they should not blind us to the common elements in all cases where other people tell us things."

5 "For the hearer to trust the speaker's word is for the hearer to ascribe authority to the speaker. Within limits of his presumed competence, the hearer ascribes to the speaker justification or warrant or knowledge for what he asserts. He takes the speaker to be in a better position to settle the matter easily and transmit the relevant information, and so he seeks the speaker's testimony (Gibbard 1990; Brandom 1994; Faulkner 2007; Keren 2007). Does the hearer have good reason to ascribe that authority? In what follows, this is referred to as the Vulnerability Problem."-Adler 2012, Section 1. It is worth pointing out that Adler views the "wide scope" of that problem to be a consequence of three facts that Govier acknowledges: (a) "our far-reaching dependence on testimony," (b) the fact that "hearers normally accept the assertions of speakers," and (c) "the typical infeasibility for hearers to seriously check or confirm either the speaker's reliability or his sincerity within the normal constraints of testimonial transmission and exchange."

(C) Robert C. Pinto. Informal Logic, Vol. 33, No. 2 (2013), pp. 263-291. 
(b) "Second, there are more specific questions about the distinction between reliable and unreliable testimony. Granted that we are justified in accepting some testimonial claims, what distinguishes justifiable from unjustifiable reliance on testimony?"

3.2 Govier's approach to the question of what justifies us in any reliance on the other people's testimony

Govier rejects (Social Trust, pp. 62-63) the idea that reliance on testimony could be justified by an appeal to our successful reliance on it in the past-by inductive logic. Like Coady, she argues that any such attempt begs the question. "The problem is that even a single person's experience presupposes reliance on testimony, and thus one cannot through experience validate the general reliability of testimony.... One's acceptance of testimony is too basic in life to be validated by induction." For her argument in support of this point, see argument (a) below, whose conclusion is that reliance on trust is "a priori.",

Adler, who had offered (2012, Section 2) the past success of reliance on testimony as part of the "background evidence" that weakens the vulnerability problem, dismisses this sort of point in Section 5 of his overview of the epistemology of testimony:

Another objection ... is that any attempt to justify testimony through an inductive inference will inevitably be circular. For the justificatory grounds will almost certainly be obtained, in part, through testimony (Coady 1992). This criticism assumes that to justify reliance on testimony overall or in a particular case, bars appeal to evidence of past testimonial success. But it is not evident that this assumption is cor-

\footnotetext{
${ }^{6}$ She explains (Social Trust, p. 61) that "[s]uch trust can be argued to be a priori because there is a sense it which it is logically prior to experience itself."

(C) Robert C. Pinto. Informal Logic, Vol. 33, No. 2 (2013), pp. 263-291.
} 
rect, or that the restriction would not equally exclude justification of perception (by its 'track record,'...).

I myself find Adler's hesitation here too brief and sketchy to be persuasive.

Though Govier rejects any attempt to justify reliance on testimony inductively, she has endorsed at least three sorts of arguments for a "general" reliance on other people's testimony. These three sorts of argument are endorsed in Govier 1993a and 1993c as well as in Social Trust. The most extended examination of such arguments is to be found in 1993c, which examines nine arguments that attempt to "validate trust in the testimony of others" (1993c, p. 23 ), and rejects six of them as invalid. The three arguments pronounced "cogent" in the conclusion of $1993 \mathrm{c}$ (p. 23) are presented again in the first part of Govier 1993a. ${ }^{7}$

(a) The argument from memory and perception. I will present this argument in more detail than the other two, since I think it is the most interesting (and I think most promising) of the three arguments. As presented in 1993c it is summarized as follows:

1. I make a distinction between veridical and non-veridical memories and perceptions.

2. To make the distinction between veridical and nonveridical memories and perceptions, I have recourse to other people [i.e., I consider my apparent perception and memories veridical just when other people tell me that they remember or perceive what I seem to remember or perceive].

\footnotetext{
7 Govier 1993a also presents an "argument from developmental necessity" which, in 1993c, was said (p. 25) to be "restricted in temporal scope" and to have "no obvious application to the question of what would justify developed knowing subjects in accepting testimonial claims." For that reason, I omit its details here.
}

(C) Robert C. Pinto. Informal Logic, Vol. 33, No. 2 (2013), pp. 263-291. 
3. To have recourse to memory and perceptual judgments of other people, I must regard (some of) their judgments as credible.

4. Therefore I must regard (some of) the memory and perceptual judgments of other people as credible.

The summary in 1993a goes a step further. It runs as follows:

1. Experience is based on memory and perception.

2. Memory and perception presuppose some trust in other people.

So,

3. What is presupposed by experience is necessary and yet cannot be established by experience.

Thus,

4. Some trust in other people is necessary and yet cannot be established by experience.

Therefore,

5. Some trust in other people is a priori.

Though this argument is not presented in detail in the section of Govier 1993 (Chapter 3, pp. 62-66) devoted to justifying our reliance on testimony, the second paragraph of that section refers the reader back to the preceding section (entitled "Social elements in basic knowledge"), where the ideas operative in this first argument are presented. And the conclusions of the second version of the argument are, in effect, summarized on p. 61 of that earlier section:

The trust in other people is so basic, in fact, that it is a condition of our having any experience at all. We need trust to observe and remember events in the world and to maintain knowledge of ourselves. Such trust can be argued to be $a$ priori because there is a sense it which it is logically prior to experience itself.

(C) Robert C. Pinto. Informal Logic, Vol. 33, No. 2 (2013), pp. 263-291. 
(b) The argument from consistency. As presented in 1993a and $1993 \mathrm{c}$, this argument is summarized as follows:

1. In normal circumstances I have reliable perception, memories and judgment.

2. I am not uniquely well-equipped epistemically

So,

3. Other people have as good a claim as I do to get things right,

Therefore,

4. In normal circumstances, other people have reliable perceptions, memories and judgment.

Govier comments on this argument (1993a, p. 20):

It is only reasonable, then, to give credence to what other people say, provided that their abilities and circumstances are favorable for accurate judgment. Consistency requires that we grant that other people make sense and get things right much of the time.

As a matter of fact, the argument as presented in 1993a and 1993c is not sufficient to warrant trust in what others tell us. As pointed out in Section 2.1 above, when we trust, our expectations have two basic dimensions: motivation (the other intends to act well and does not intend to do harm) and competence. The argument as presented in these two papers may provide grounds for supposing that others have the competence to judge correctly, but it provides no grounds for supposing that others are, or are likely to be, properly motivated to tell the truth as they know or believe it to be.

A slightly different version of the argument from consistency is presented in Social Trust (pp. 65-66), which is not subject to the criticism just made. For one thing, that later version of the argument turns on the idea that we ought to treat others as we want them to treat us (together with the idea that we want others to believe what we tell them). For another, it is supplemented with an ethical dimension drawn from Price 1969 (pp. 114-15), which cul-

(C) Robert C. Pinto. Informal Logic, Vol. 33, No. 2 (2013), pp. 263-291. 
minates in the claim that "every person, just because he is a person, has a prima facie right to be believed when he makes a statement."

(c) The argument from mundane asking and telling. As presented in 1993a and 1993c, this argument is summarized as follows:

1. Society (at least in its western forms) presumes social practices of mundane asking and telling.

2. Mundane asking and telling presume that people generally trust each other for mundane answers.

So,

3. Society (at least in its western forms) presumes that people generally trust each other for mundane answers.

4. Society in its western forms, exists.

Therefore,

5. People in western societies generally trust each other for mundane answers.

About this argument Govier comments (1993a, p. 21)

Does this argument show categorically that people should trust and believe others? Not exactly. At least it does not show that all people in all societies should do so. It shows that we must do so if we think there is any point in asking mundane questions.

Personally, I am strongly inclined to agree with Govier that what Adler (2012) called "reductionist attempts" to justify reliance on testimony are undermined, as Govier claims, by questionbegging. And I think that Govier's argument from perception and memory has considerable merit - that our disposition to rely on the testimony of others is so basic to our cognitive practices that it cannot coherently be called into question. However, I am less sanguine about the prospects of the arguments from consistency and from mundane asking and telling, as described here.

(C) Robert C. Pinto. Informal Logic, Vol. 33, No. 2 (2013), pp. 263-291. 
It is perhaps worth pointing out that there are other, very different approaches to understanding the rationality of accepting testimony besides Govier's attempts and the attempt at an "inductive justification" of the reliability of testimony. For example Kauffeld (2003a and 2003b) treats the problem as one of understanding the grounds for what he calls the "presumption of veracity," which he bases on his general account of presumption. About presumption in general he says, (2003a, pp. 140-41)

In presuming that $p$ a person comes to hold that $p$ by reason of the supposition that some person has or will have made it the case that $p$ rather than risk resentment for acting otherwise. A presumption is a conclusion which is held on this basis or is available on the back of such a reason. ${ }^{8}$

In 2003 b (p.10) Kauffeld links the "presumption of veracity" to such a reason:

Thus, when $\mathbf{S}$ deliberately and openly manifests her primary speaker intention, she openly takes responsibility for her communicative effort and its foreseeable consequence(s), e.g., the possibility that $\mathbf{A}$ might believe what $\mathbf{S}$ says. $\mathbf{S}$ thereby generates a presumption of veracity on behalf of what she says. For given what $\mathbf{S}$ has made known to $\mathbf{A}$ about her intentions, $\mathbf{A}$ can reason (and be expected) to reason as follows: $\mathbf{S}$ has placed herself in a position where $\mathbf{S}$ cannot very well deny responsibility for trying to get me to, e. g., believe that $\mathbf{P} ; \mathbf{S}$ is no fool; $\mathbf{S}$ would not be willing to brook criticism and resentment for trying to get me to believe something which $\mathbf{S}$ does not herself believe on the basis of some good effort to ascertain its truth. So I may fairly presume that $\mathbf{P}$.

(See also the quotation in note 10 below.) When Adler (2012,

\footnotetext{
${ }^{8}$ In $2003 \mathrm{a}$, p. 141, note 5 , he says he is 'using 'resentment' in the ordinary sense which encompasses the sense of injury and ill-will persons feel toward the authors of a wrong or affront."

(C) Robert C. Pinto. Informal Logic, Vol. 33, No. 2 (2013), pp. 263-291.
} 
Section 2, item 3) cites "Reputation and Sanctions" as part of the background evidence that bears on the vulnerability problem, he makes a point that invokes elements of Kauffeld's approach.

Goldman (1999, Chapter 4), while defending (pp. 109-125) a Bayesian account of inferential practices regarding testimony, describes (pp. 128-130) four distinct approaches to the philosophical "justification of testimonial belief," without committing himself to which of the four should be endorsed. He begins by noting Coady's arguments against "reductionist" accounts, which attempt an "inductivist" approach to justifying those practices. He disaproves of some of Coady's arguments but finds possible merit in others, and concludes by saying (p. 127) that "[a]t a minimum, this antireductionist conclusion has a lot going for it."

\subsection{Implicit trust: The "default mechanism"}

What about the "second level" of questions about testimony, namely "specific questions about the distinction between reliable and unreliable testimony." In Chapter 3 of Social Trust, the core idea that guides what she has to say in respect of such questions is introduced at the end of the section entitled "Justifying our reliance on testimony." Having quoted Price (1969, p. 114) — "Surely every person, just because he is a person, has at least a prima facie claim to be believed when he makes a statement"-she comments (Social Trust, p. 66):

\footnotetext{
9 Adler comments, "The expectation of truthfulness is sufficiently strong that those who are the victims of false testimony, whether through error or deception, are likely to become less trusting. But the scope of that loss of trust will be extremely narrowly circumscribed, partly because we lack other means than testimony to acquire the information we seek. In small communities and institutional settings, though far less so in large communities where anonymity can be maintained, sanctions and reputation are a forceful constraint. "Gossip" columnists probably would not keep their jobs, if the readily verified portions of their factual reports were not largely accurate."
}

(C) Robert C. Pinto. Informal Logic, Vol. 33, No. 2 (2013), pp. 263-291. 


\section{Robert C. Pinto}

In the absence of any special reason to the contrary, when another person tells us something, we should trust her enough to accept it. Taking another at her word is the automatic, normal thing to do-the default mechanism, we might say - and we deviate from this approach only when we have specific reason to do so.

And, as I indicated above in section 2.4, what she calls "Implicit trust," as differentiated from the "innocent trust" typical of children, is marked by the fact that for adults "[t]rust and acceptance constitute a kind of default system, operative unless there is reason to pause and reflect."

However, Govier does not, as far as I can see, attempt a defense of this "default mechanism"-beyond a reliance on the ethical considerations drawn from Price that she cites on p. 65 (and that were quoted in the preceding paragraph). Nevertheless, such a default practice seems to be fairly widely endorsed among those who have addressed issues surrounding testimony. See for example Adler's (2012, Section 3) discussion of a putative default rule for testimony $(D R)$, which he formulates as

If the speaker $S$ asserts that $p$ to the hearer $H$, then, under normal conditions, it is correct for $H$ to accept (believe) $S$ 's assertion, unless $H$ has special reason to object. ${ }^{10}$

Moreover, Adler himself suggests that DR derives direct epistemic support if a certain thesis he labels the K-norm holds:

(K-norm): One correctly asserts that $p$ only if one knows (or represents oneself as knowing) that $p$.

\footnotetext{
${ }^{10}$ Adler notes: "The $D R$ is not the weakest principle that might govern conversational acceptance. Rather than holding that testimony transmits warrant or justification or knowledge, a weaker claim is that it yields to the hearer only some (pro tanto) epistemic reason to believe the speaker's assertion. But this weaker version of the $D R$ would yield only entitlement to qualified, not all-out, acceptance. The result is weaker than conversational practice reveals."

(C) Robert C. Pinto. Informal Logic, Vol. 33, No. 2 (2013), pp. 263-291.
} 
Adler comments:

On the assumption that speakers generally conform to the $\mathrm{K}$ norm, which would help explain why the norm continues to hold, hearers will correspondingly ascribe to speakers knowledge that their assertion holds. This ascription supports the $D R$, since a speaker's knowing is excellent reason to accept his assertion. ${ }^{11}$

Nevertheless, some discussion of the pros and cons of the default rule seems in order here. For as Adler (2012, Section 6.2) points out, there are dissenters. He calls attention to Elizabeth Fricker's condemnation of it:

With qualifications, Fricker denies that we are entitled to default-accept the reliability of testimony, although she does think a default applies to judging the sincerity of the speaker. She regards any rule like the DR as "an epistemic charter for the gullible and undiscriminating" (1994, 126; but see also, 1995). Fricker claims that hearers can obtain independent evidence to confirm the belief that a speaker is trustworthy. She stresses that "insincerity and honest error are both perfectly possible":

a hearer should always engage in some assessment of the speaker for trustworthiness. To believe what is asserted without doing so is to believe blindly, uncritically. This is gullibility. (145)

If we concede (as apparently Fricker does and as I certainly do) that one ought to presume a speaker is sincere in the absence of a

${ }^{11}$ Kauffeld 2003a (p. 144) suggests something somewhat similar, namely that obligations undertaken by a speaker who makes an assertion warrant a presumption of veracity on the part of a hearer: “. .. a broadly Gricean analysis of utterance-meaning shows that speech acts are performed by speakers deliberately and openly undertaking obligations and, thereby, generating special presumptions .... In the simple case of seriously saying something a speaker openly undertakes responsibility for the truthfulness of her utterance and, thereby, engages a special presumption of veracity."

(C) Robert C. Pinto. Informal Logic, Vol. 33, No. 2 (2013), pp. 263-291. 


\section{Robert C. Pinto}

reason to believe otherwise, the issue becomes whether one ought to presume the speaker knows what he or she is talking about in the absence of a reason to withhold that presumption. Whether one ought to so presume depends on what is to count as a reason to withhold that presumption pending further investigation. In Social Trust $(\mathrm{p}, 67)$ the examples of reasons to withhold trust in testimony explicitly mentioned are, in addition to reasons for suspecting insincerity, (i) that what the speaker says is implausible or conflicts with what we believe or think we know and (ii) that "the other person may seem biased, tired, pushy, overly emotional, ... incoherent, unintelligent, manipulative...."

But I think there are-even in casual conversationadditional, quite different factors that should influence whether we pause and reflect. Thus (iii) Price (1969, p. 113) mentions one such, when he says:

The answer to some very important question, practical or theoretical, may depend on the correctness of so-and-so's testimony. Then we shall be more cautious. ${ }^{12}$

I need not suspect my physician of insincerity or lack of competence to request a second opinion when she tells me that back surgery is the only thing that will solve my problem. (iv) As I pointed out in Pinto 2003 (p. 6), decisions about whether to withhold acceptance a proposition at a given point "must take into account the 'costs' of securing further information or further scrutiny (including the possibility of lost opportunities as a result of deferring judgment)"- see also Freeman 2003 on this point. (v) When we know that what the speaker says broaches a controversial topic (claims, for example, that a three-week-old fetus is a full-fledged human person), we would be ill-advised to accept what the speaker says on her say-so - even though we ourselves might have no view

\footnotetext{
12 Actually, Govier (1997, p.68) does acknowledge something of this sort when she says, "The issue of competence varies, depending on what is claimed and how important it is to be accurate."

(C) Robert C. Pinto. Informal Logic, Vol. 33, No. 2 (2013), pp. 263-291.
} 
on the matter with which the speaker's statement might conflict and do not consider the claim implausible.

In addition, (vi) there are special problems concerned with relying on experts, to which Govier devotes a section near the end of Chapter 3 (Social Trust, pp. 69-72). As well, (vii) Govier herself (Social Trust, Chapter 4, esp. pp. 92-104) discusses special problems associated with trusting professionals. Moreover, any simple formulation of a default rule or "method" overlooks something that Govier has stressed in contexts not concerned specifically with testimony, namely that whether trust is reasonable depends on the social context in which we find ourselves - on whether, for example, honesty is widespread among those we are dealing with in that context (see for example the passage quoted at the end of Section 2.5 above). Finally, I can't help being puzzled by the fact that although she endorses a default "method" when it comes to testimony in Chapter 3 of Social Trust, in Chapter 5 she appears to object to a default method for trusting strangers (see Section 2.5 above).

Despite these reservations, Fricker's claims that any rule like DR is "an epistemic charter for the gullible and undiscriminating" and that "a hearer should always engage in some assessment of the speaker for trustworthiness" (emphasis added) strike me as exaggerations. At the same time, it seems to me that-given the indefiniteness of what is to count as "a special reason to object"- the default "rule" is not much of a rule. Govier is wise to speak instead of a "default method" or a "default mechanism"- a phrase that better captures much of our practice in dealing with testimony: we normally simply accept what we're told by others unless a "warning light" turns on, urging us to proceed with caution. And I am inclined to think that what we should make of that "mechanism" is something that calls for further investigation.

\subsection{Reflective trust}

Govier 1993a presents two "models" for acceptance of a proposition on the basis of testimony. The models are attempts to capture 


\section{Robert C. Pinto}

our reasoning from the fact that someone has told us something to our believing what we've been told. The first model, which is operative in "implicit trust," is called the Simple Acceptance Model and is described (p. 22) as follows:
1. $S$ tells me that $p$
2. I believe $S$
So,
3. $\mathrm{P}$

Govier says of premise 2

I come to know or believe a proposition because I believe someone. Believing that person presupposes trusting her and trust in such a case is unquestioning, implicit and complete.

For cases where we don't rely on implicit trust, we can (1993a. p. 23) "critically evaluate what we are told by reflecting on the communicative style, competence, and honesty of the other person and on the independent plausibility of what they say." When testimonial claims are critically appraised another kind of trust is involved. For such cases Govier provides a "Reflective Appraisal Model""13 intended to capture the steps in the critical evaluation that leads from the fact that someone has told me that $p$ to my acceptance of $p$ :

${ }^{13}$ In Govier 1993d the same model is presented, though there it is called a "Universalistic Reflective Model." In 1993d Govier is addressing that fact that (p. 93) "[f]eminist theorists allege that standards couched in universalistic terms are often implicitly racist and sexist. Universalistic theories, they claim, hide differences that relevantly affect how people have suffered in the past, are treated, and should be treated." Govier's strategy is to show that even in cases where testimony is treated in a racist or sexist way, a universalistic model can help identify the points in racist or sexist reasoning at which those abuses occur. She says (p. 99) that "the problem of rejecting testimony on the basis of gender, race, class, or other prejudice is a serious one" and in the final pages of the paper offers an approach for addressing the problem.

(C) Robert C. Pinto. Informal Logic, Vol. 33, No. 2 (2013), pp. 263-291. 
1. A says " $p . "$

2. In saying " $p$ " $A$ asserts that $p$.

3. $A$ is sincere and truthful in his or her assertion that $p$. So,

4. $A$ believes that $p$.

5. $A$ is (in the normative sense) competent and reliable with regard to such matters as $p$.

Thus,

6. There is good reason to believe that $p$.

7. There is no compelling reason or evidence against $p$.

Therefore, probably,

8. $p$.

Though this model is not reproduced in Social Trust, it captures a point that Govier makes on p. 68 of that work:

With reflective trust there are three strands for consideration: first, the saying or "speech act"; second, competence; and third, sincerity.

Step 2 of the second model captures the fact that a hearer (1993a, p. 23) "based on verbal and communicative knowledge, including contextual understanding" must determine that "in saying what he did, in the context and in the way that he did, $A$ was seriously asserting p." Step 3 addresses the question of sincerity. Govier says (1993a, p 23-24) that acceptance of this premise

is grounded both on one's sense of $A$ in general and interpretation of his words, body language, and purpose in this context. This premise requires one kind of trust in $A$ : one's sense that he is not being deceptive or manipulative in this case, that he is being sincere.

Step 5 addresses the question of A's competence-which articulates a second "dimension of trust." Govier says (1993a, p. 24),

(C) Robert C. Pinto. Informal Logic, Vol. 33, No. 2 (2013), pp. 263-291. 
Evidence for premise (5) may be based on his track record with regard to similar claims made in the past; when such evidence is not available, we may form a judgment about $A$ 's competence from our impressions on this particular occasion. $^{14}$

Steps 6 through 8 illustrate the point made in Social Trust (p. 68) about reflective trust:

Given that we judge a speaker to be competent and sincere and to be making an assertion, we will believe him or her unless we have countervailing reasons not to believe. In such cases we do not trust without question, but in the end we still trust. Without trust we would not believe the person; we would not judge that his or her belief gives us a reason to believe. It is not unhesitatingly assumed. But it is still trust.

\section{Conclusion}

For those whose interests lie in informal logic and argumentation theory, the aspect of Govier's work on trust that will be of most immediate interest lies in its bearing on reasons for trusting.

(a) I hope that in this paper I've succeeded in making it clear that what Govier has said about such reasons - both with regard to reasons for trusting those who offer testimony and with respect to reasons for trusting in a host of other aspects of life not directly concerned with testimony-is sufficiently articulated to merit serious consideration. I hope I've also made it clear that outstanding questions remain about reasons for trusting, and that interacting with what Govier has to say about such reasons ought to be part of addressing those outstanding questions.

\footnotetext{
14 Though she says (Govier 1997, p 68), "Contexts where expertise is more technical and specialized, such as economics or medicine, raise more complex questions of competence."

(C) Robert C. Pinto. Informal Logic, Vol. 33, No. 2 (2013), pp. 263-291.
} 
(b) Any serious attempt to investigate reasons for trusting (i) requires an understanding of what trust is and (ii) must be sensitive to the differences in the roles it plays in different contexts and the different problems posed by those different roles. I hope I've succeeded in making it clear that Govier's extensive and detailed work on trust sheds enormous light on what trust is and on the different roles it plays in different contexts. This aspect of her work makes it an almost essential propaedeutic to any successful investigation of reasons for trusting.

\section{References}

Adler, J. (2012). Epistemological problems of testimony. Stanford Encyclopedia of Philosophy at URL http://

http://plato.stanford.edu/entries/testimony-episprob/. An entry on this topic was first published in February 2006; the Encyclopedia reports that the August 2012 update was completed by Adler before he passed away.

Anscombe, E. (1979). What is it to believe someone? In

C.F.Delaney (ed.), Rationality and Religious Belief (Notre

Dame: University of Notre Dame Press), pp. 141-151.

Coady, C. A. J. (1992). Testimony: A Philosophical Study, Oxford:

Oxford University Press.

Freeman, J. (2003). The pragmatic dimension of premise acceptability. In van Eemeren, Blair, Willand and Snoekck Henkemans, (eds.), Anyone Who Has a View (Dordrecht: Kluwer), pp. 17-26.

Friend, C. (2000). Review of Social Trust and Human Communities by Trudy Govier. Informal Logic 20, pp. 85-88.

Fricker, E. (1994). Against Gullibility. In Matilal and Chakrabarti (eds.) Knowing from Words (Boston: Kluwer), pp. 125161.

(C) Robert C. Pinto. Informal Logic, Vol. 33, No. 2 (2013), pp. 263-291. 
— (1995). Critical Notice: Telling and Trusting: Reductionism and Anti-Reductionism in the Epistemology of Testimony. Mind 104, pp. 393-411.

Govier, T. (1992a). Distrust as a practical problem. Journal of Social Philosophy, pp. 52-63.

— (1992b). Trust, distrust, and feminist theory. Hypatia, Vol. 7 , No. 1 (Winter,), pp. 16-33.

— (1993a). Needing each other for knowledge: reflections on trust and testimony. In Erik C. W. Krabbe, Renée José Dalitz and Pier A. Smit (eds),. Empirical Logic and Public Debate: Essays in Honour of Else M. Barth (Amsterdam and Atlanta GA: Rodopi), pp. 13-26.

- (1993b). Self-Trust, autonomy, and self-esteem. Hypatia, Vol.

8, No. 1 (Winter,), pp. 99-120.

- (1993c). Trust and testimony: nine arguments on testimonial knowledge. International Journal of Moral and Social Studies 8, 21-39

— (1993d). When logic meets politics: testimony, distrust, and rhetorical disadvantage. Informal Logic 15, pp. 93-104. Reprinted as chapter 3 of Trudy Govier, The Philosophy of Argument (Newport News, VA: Vale Press, 1999).

- (1994). Is it a jungle out there? Trust, distrust and the construction of social reality. Dialogue 33 (02), pp. 237-252.

— (1996). Trust and totalitarianism: some suggestive examples.

Journal of Social Philosophy 27, pp. 149-63.

- (1997). Social Trust and Human Communities. Montreal and

Kingston: McGill-Queen's University Press.

- (1998). Dilemmas of Trust. Montreal and Kingston: McGillQueen's University Press.

- (2011). Hope and its opposites. Journal of Social Philosophy 42, pp. 239-253. 
Govier, T. \& W. Verwoerd (2002). Trust and the problem of national reconciliation. Philosophy of the Social Sciences 32 (2):178-205.

Hardwig, J. (1988). Depending on experts. In Trudy Govier, (ed.), Selected Issues in Logic and Communication (Belmont, CA: Wadsworth), pp. 125-37.

Kauffeld, F. J. (2003a). The Ordinary Practice of Presuming and Presumption with Special Attention to Veracity and the Burden of Proof. In van Eemeren, Blair, Willard and Snoekck Henkemans (eds,), Anyone Who Has a View (Dordrecht: Kluwer). pp. 133-146.

Kauffeld, F. J. (2003b). The Presumption of Veracity in Testimony and Gossip. In Blair, Farr, Hansen, Johnson and Tindale, InformalLogic@ 25 (Windsor, Ontario: OSSA).

Logstrup, K. E. (1997). The Ethical Demand. Trans. Fru Marie Logstrup. Notre Dame: University of Notre Dame Press. Price, H.H. (1969). Belief. London: George Allen and Unwin.

Rotter, J. (1980). Interpersonal Trust, Trustworthiness, and Gullibility. American Psychologist 35, pp. 1-17.

Rescher, N. (1988). Rationality. Oxford: Clarendon Press.

Sharpin, S. The Social History of Truth: Civility in Science in Seventeenth Century England (University of Chicago Press). 